\title{
In vitro Antibiotic Sensitivity Pattern of Staphylococcus aureus and Coagulase Negative Staphylococci Isolated from Bovine Mastitis
}

\author{
A.G. Bhagat ${ }^{1}$, H.N. Kher ${ }^{2}$, A.I. Dadawala ${ }^{3}$, H.C. Chauhan ${ }^{2}$, M.D. Shrimali ${ }^{2}$, \\ K.B. Patel ${ }^{2}$, B.K. Patel ${ }^{2}$, M.A. Patel ${ }^{2}$ and B.S. Chandel ${ }^{2}$
}

${ }^{I}$ Department of Microbiology, College of Basic science and Humanities, Sardarkrushinagar

Dantiwada Agricultural University, Sardarkrushinagar-385 506, Gujarat, India

${ }^{2}$ Department of Veterinary Microbiology/Animal Biotechnology, College of Veterinary

Science and Animal Husbandry, Sardarkrushinagar Dantiwada Agricultural University,

Sardarkrushinagar-385 506, Gujarat, India

${ }^{3}$ Department of Microbiology, Kamdhenu University, India

*Corresponding author

\section{A B S T R A C T}

\begin{tabular}{|l|}
\hline K ey w or d s \\
$\begin{array}{l}\text { S. aureus, CoNS, } \\
\text { Mastitis, Antibiotic }\end{array}$ \\
\hline Article Info \\
\hline $\begin{array}{l}\text { Accepted: } \\
\text { 20 September } 2018 \\
\text { Available Online: } \\
10 \text { October } 2018\end{array}$ \\
\hline
\end{tabular}

Staphylococcal mastitis is a major and costly problem of dairy cattle all over the world. In the present study, Clinical $(n=165)$ and sub-clinical mastitic milk samples were processed for bacterial isolation. All the 83 isolates recovered on primary isolation were confirmed as Staphylococcus spp. based on morphological and biochemical characteristics. Based on the result of tube coagulase test, $55(66.27 \%)$ isolates were considered as a Staphylococcus aureus, whereas $28(33.73 \%)$ isolates were considered as Coagulase-negative staphylococci (CoNS). Among the 12 antibiotics tested, highest resistance was noticed to penicillin to the extent of 60.00 per cent among Staphylococcus aureus and 82.14 per cent in CoNS isolates whereas Aminopenicillins i.e., ampicillin-sulbactam tested in this study showed maximum effectiveness of 98.18 and 96.43 per cent towards Staphylococcus aureus and CoNS isolates, respectively.

\section{Introduction}

Mastitis is one of the most crucial diseases of cattle and buffalo because it causes innumerable problems to milk production, milk processing and quality of milk and milk products which results in huge economic losses to the dairy industry. The physical, chemical, bacteriological and other qualities of milk are affected by mastitis. An annual economic loss of over 4300 crore INR due to mastitis is reported (Ranjan, 2010), out of which 70 percent could be attributed to subclinical mastitis (Hamadani et al., 2014). Staphylococcus aureus is the most common etiological pathogen of contagious bovine mastitis and it has the potential to develop resistance to almost all the antimicrobial agents (Barkema et al., 2009). These organisms are well known for their tolerance to wide range of adverse circumstances. Staphylococci comprise 45 species and 21 subspecies (Bergeron et al., 2011). In addition to Staphylococcus aureus, coagulase-negative 
staphylococci (CoNS) are increasingly becoming recognized as etiologic agents associated with intramammary infections (IMI) in most countries. Antimicrobial therapy is one of the measures for controlling staphylococcal mastitis. The determination of antimicrobial susceptibility of clinical isolates is required not only for therapy, but also for monitoring the spread of resistant strains throughout the populations. Although antimicrobial susceptibility testing is a valuable tool in determining the best therapeutic choice against a mastitis pathogen in practice, it is rarely performed and therapy decisions are usually made empirically.

Therefore, susceptibility data for a large number of isolates in an area or region can be useful to veterinarians (Salmon, 2002). The resistance of Staphylococcus aureus to antimicrobial agents has been extensively documented and it contributed significantly to the treatment failure (Kumar et al., 2010). Beside S. aureus, CoNS isolates can also harbour resistant genes to several antimicrobials (Silva et al., 2013). Hence, present study was designed to evaluate In vitro antibiotic sensitivity of Staphylococcus aureus and coagulase negative staphylococci bacterial species isolated from cases of mastitis against range of antibiotics potentially useful in mastitis treatment and control programs carried out in field.

\section{Materials and Methods}

\section{Collection of milk samples}

A total of 165 milk samples from suspected cases of clinical mastitis in cows and buffaloes belonging to North Gujarat were collected aseptically in sterilized vials. In addition, a total of 256 milk samples from cows $(\mathrm{n}=198)$ and buffaloes $(\mathrm{n}=58)$ belonging to North Gujarat were also collected aseptically for screening of sub-clinical mastitis.

\section{Screening of sub-clinical mastitis}

All the milk samples $(n=256)$ were screened for sub-clinical mastitis (SCM) by California Mastitis Test (CMT) as per the procedure described by Schalm and Noorlander (1957).

\section{Bacterial isolation, identification and biochemical characterization}

Samples which were detected positive in subclinical mastitis and the samples from clinical cases were processed for isolation of Staphylococcus. Milk samples were inoculated on the plates of nutrient agar by spreading heavy inoculums of thoroughly mixed milk. The plates were incubated at $37^{\circ} \mathrm{C}$ for 24 hours. Thereafter, golden yellow pigmented or white colour colony indicative of presumptive Staphylococcus were transferred to mannitol salt agar which is considered as selective medium for Staphylococcus. The colonies of Staphylococcus, forming yellow and red colouration indicative of mannitol fermentation and non-fermentation, respectively were transferred to nutrient Agar slants for further identification. The isolates were identified by morphological characteristics and Biochemical characterization as per the methods described by Buchanan and Gibson (1974) and Cowan and Steel (1974). Different biochemical tests such as catalase, oxidase, phosphatase, maltose fermentation and coagulase test were performed. The coagulase positive isolates were considered as a Staphylococcus aureus whereas the isolates, negative by coagulase test, were considered as a coagulase negative staphylococci.

\section{Antibiotic sensitivity patterns of isolates}

All the isolates obtained were subjected to in vitro antibiotic sensitivity test, as per the method described by Bauer et al., (1966). Each test strain was grown in BHI broth 
overnight at $37^{\circ} \mathrm{C}$. Sterile plates of Mueller and Hinton agar were seeded with about $1 \mathrm{ml}$ of inoculums and were allowed to dry. Monodiscs (Hi Media, Pvt. Ltd., Mumbai) of antibiotics viz., Penicillin G (10 Units), Ciprofloxacin $(30 \mathrm{mcg})$, Gentamicin $(10 \mathrm{mcg})$, Enrofloxacin $(10 \mathrm{mcg})$, Chloramphenicol $(25$ $\mathrm{mcg}$ ), Ciphalexin (30 mcg), AmpicillinSulbactam (10/10 mcg), Ampicillin (10 mcg), Amoxycillin-Clavulanic acid (30 mcg), Streptomycin $(25 \mathrm{mcg})$ Methicillin $(10 \mathrm{mcg})$, Oxacillin $(5 \mathrm{mcg})$ were then placed in the plate and were incubated aerobically at $37^{\circ} \mathrm{C}$ overnight. Zones of inhibition were measured and compared with zone size interpretative table furnished by the manufacturer and graded as either sensitive or resistant.

\section{Results and Discussion}

Thirty-four samples which were found positive for sub-clinical mastitis by California mastitis test and 165 samples of clinical mastitis were inoculated on Nutrient Agar for primary isolation. All the 83 isolates, recovered in primary isolation, were inoculated on Mannitol Salt Agar (MSA), wherein 78 isolates showed mannitol fermentation. In the present study, all the 83 presumptive strains of Staphylococcus isolates were subjected to Gram's staining and various bio-chemical reactions for further identification. In Gram's stained culture smears under microscope, all the 83 isolates revealed spherical and irregular clusters like bunch of grapes. On bio-chemical characterisation, all the 83 isolates were Catalase positive, Oxidase negative and positive for Maltose fermentation and Phosphatase production. In light of these tests, a total of 83 isolates were confirmed as Staphylococcus spp. Similar phenotypic methods were also employed by Kumar et al., (2010); Momtaz et al., (2010); Medeiros et al., (2011) and Rusenova et al., (2013) for the identification of Staphylococcus spp.
Bovine mastitis is the most common and the quite damaging disease throughout the world. It is a versatile disease in milch animals and is caused by pathological, genetical, physiological or environmental factors. Inspite of the concerted efforts to control or reduce the incidence of mastitis for decades, it still remains a major threat to the dairy industry causing huge economic loss. In India, 50.00 per cent of milch animals are affected with mastitis, out of which clinical mastitis is accounted for 10.00 per cent with annual economic loss of approximately 6000 crores (Dua, 2001). It is a multietiological disease, but the prevalence of pathogenic and antibiotic resistant strains of Staphylococcus aureus causing bovine mastitis is serious cause of concern in south Asian countries including India as these animals are significant contributor to milk production (El-Jakee et al., 2010).

Staphylococcus is usually divided into two groups based on the ability to produce coagulase, an extracellular enzyme that clots blood plasma. The coagulase positive group that includes $S$. aureus, S. intermedius and some strains of Staphylococcus hyicus, whereas coagulase negative Staphylococcus (CoNS) is a large and heterogeneous group that contain more than 40 species and subspecies of Staphylococcus (Holt et al., 1994).

Coagulase produced from Staphylococcus aureus is a single chain protein with a molecular weight of $61,000 \mathrm{~d}$ (Bas et al., 1974). Coagulase forms a complex by binding with protein which has thrombin-like activity that converts fibrinogen to fibrin (McDevitt $e t$ al., 1992). Coagulase is of two types, one bound to cell wall responsible for clotting of plasma in slide test and another secreted as free coagulase in the media responsible for clotting of plasma in tube test (Duthie, 1954). Virulence of Staphylococcus aureus depends 
upon its ability to produce coagulase, but not with its ability to coagulate plasma. It is postulated that coagulase might function in some way to protect organism against the antibacterial activity of plasma which can contribute to its virulence. Coagulase is encoded by coa gene and is considered as one of the important criteria for identification of this type of organism. Many of the laboratories have utilised this property along with its combination with other tests like fermentation on MSA and production of Catalase and DNase enzymes (Kateete et al., 2010).

In the present study, all the 83 Staphylococcus isolates were subjected to tube coagulase test by using rabbit plasma. Out of 83 isolates, 55 $(66.27 \%)$ isolates were found to be positive for coagulase production and were considered as a Staphylococcus aureus, whereas 28 $(33.73 \%)$ isolates were found negative hence they were tentatively considered as a CoNS.

\section{In-vitro antibiotic sensitivity test}

One important reason for therapy failure in the management of mastitis could arise from various factors involving the pathological changes in the udder, etiology, lower efficacy of antimicrobials and improper veterinary services (Adesola, 2012). But above all, antimicrobial susceptibility testing, typically using a disk diffusion assay is often performed as part of the routine laboratory evaluation with an attempt to provide guidelines for the treatment of mastitis, especially the pathogens causing clinical and sub-clinical mastitis and thus forming a crucial part in development of mastitis control program. World Health Organisation for animal health has also recommended monitoring and observation of efficacy of antimicrobials towards pathogenic and commensal bacteria affecting animals (Acar and Rostel, 2001). In a particular region, antibiotic susceptibility/resistance in bacterial isolates varies due to different strategies and policies in containment programmes of mastitis. The isolation of organism and choice of antimicrobial agent is often considered empirical in the management of mastitis. Thus in the present study, antibiogram of $S$. aureus and CoNS isolates was analysed to find out the status or information on the sensitivity/resistance patterns among the isolates. Antibiogram trend of twelve commonly used antimicrobial drugs for treatment of bovine mastitis is presented in Table 1.

In the present study, only 14 (16.87 \%) isolates viz., 12 Staphylococcus aureus and 2 CoNS were susceptible to all antibiotics tested, while the remaining $69(83.13 \%)$ isolates were resistant at least to one of the antibiotics which corroborates the finding of Turutoglu et al., (2006) who reported that 14.64 per cent Staphylococcus isolates were susceptible to all antibiotics tested.

However, in contrast to the present study, higher susceptibility rates of staphylococcal isolates were reported in some countries (Gentilini et al., 2002; Kaszanyitzky et al., 2003 and Rajala-Schultz et al., 2004). This might be attributed to misuse of antibacterial agents in India, where these are practically dispensed without a prescription. In cases of mastitis, the wrong or incomplete duration of treatment of animals and indiscriminate and injudicious use of antibiotics also contribute significantly to the development of bacterial resistance against them (Turutoglu et al., 2006).

Among the 12 antibiotics tested, highest resistance was noticed to penicillin to the extent of 60.00 per cent among Staphylococcus aureus and 82.14 per cent in CoNS isolates. Similarly, 56.37 per cent of Staphylococcus aureus and 71.43 per cent of the CoNS isolates were resistant to ampicillin. 
Table.1 Antibiogram trend of coagulase positive and negative Staphylococcus isolates against antibiotics

\begin{tabular}{|c|c|c|c|c|c|c|}
\hline \multirow{4}{*}{$\begin{array}{l}\text { Sr. } \\
\text { No. } \\
1\end{array}$} & \multirow{4}{*}{$\begin{array}{l}\text { Antibiotics } \\
\text { Penicillin G }\end{array}$} & \multirow{2}{*}{\multicolumn{3}{|c|}{$\begin{array}{l}\text { No. of Staphylococcus aureus } \\
\text { isolates }(\mathrm{n}=55)\end{array}$}} & \multicolumn{2}{|c|}{ No. of CoNS isolates $(\mathrm{n}=28)$} \\
\hline & & & & & \multirow[b]{2}{*}{ Sensitive } & \multirow{3}{*}{\begin{tabular}{|l|} 
Resistant \\
$23(82.14 \%)$ \\
\end{tabular}} \\
\hline & & \multirow{2}{*}{$\begin{array}{l}\text { Sensitive } \\
22(40.00 \%)\end{array}$} & \multicolumn{2}{|c|}{ Resistant } & & \\
\hline & & & 33 & $(60.00 \%)$ & $05(17.86 \%)$ & \\
\hline 2 & Methicillin & $48(87.27 \%)$ & 07 & $(12.73 \%)$ & $21(75.00 \%)$ & $07(25.00 \%)$ \\
\hline 3 & Oxacillin & $48(87.27 \%)$ & 07 & $(12.73 \%)$ & $21(75.00 \%)$ & $07(25.00 \%)$ \\
\hline 4 & & $24(43.63 \%)$ & 31 & & & $20(71.43 \%)$ \\
\hline 5 & Ampicillin-Sul & $54(98.18 \%)$ & 01 & $(01$. & $27(96.43 \%)$ & $01(03.57 \%)$ \\
\hline 6 & Amoxycillin-Clavulanic & $38(69.09 \%)$ & 17 & $(30.91 \%)$ & $21(75.00 \%)$ & $07(25.00 \%)$ \\
\hline 7 & Strept & $45(\varepsilon$ & 10 & & 18 & $1 \%)$ \\
\hline 8 & Gentamicin & $46(83.64 \%)$ & 09 & & $27(96.43 \%)$ & $01(03.57 \%)$ \\
\hline 9 & Ciprofloxacin & $24(43.63 \%)$ & 31 & $(56.37 \%)$ & $06(21.43 \%)$ & $22(78.57 \%)$ \\
\hline 10 & Enrofloxacin & $40(72.73 \%)$ & 15 & & $17(60.71 \%)$ & $11(39.29 \%)$ \\
\hline 11 & Chloramphenicol & $48(87.27 \%)$ & 07 & $(12.73 \%)$ & $24(85.71 \%)$ & $04(14.29 \%)$ \\
\hline 12 & Ciphalexin & $52(94.55 \%)$ & 03 & $(05.45 \%)$ & $22(78.57 \%)$ & $06(21.43 \%)$ \\
\hline
\end{tabular}

In accordance to the present study, 87.00, 94.4 and 100.00 per cent resistance to penicillin was reported by Ebrahimi and Taheri (2009); Abera et al., (2013) and Thaker et al., (2013), respectively. Whereas, higher resistance of 83.00 and 73.30 per cent to Ampicillin was also reported by Mekonnen et al., (2005) and Murugaiyah et al., (2014), respectively.

A large number of the isolates were found to be resistant to long ago established antibiotics (penicillin $G$ and ampicillin) compared to susceptibility of the isolates to the more recently developed compounds (ampicillinsulbactum, amoxycillin-clavulanic acid, enrofloxacin and cephalexin).

In the present study, resistance to penicillin and ampicillin must be of concern because these antibiotics represent the main antibiotic group recommended for the treatment of staphylococcal mastitis. The resistance of
Staphylococcus to penicillin and ampicillin might be attributed to the production of $\beta$ lactamase, an enzyme that inactivates penicillin and closely related antibiotics (Abera et al., 2010).

Regular use of antibiotics for the treatment of cows and buffaloes may result in the spread of resistant strains. These results suggest that penicillin and ampicillin might not be a proper choice for treatment of mastitis caused by Staphylococcus. Similar observations have also been made by Abera et al., (2013), Thaker et al., (2013) and Parth (2016).

Aminopenicillins i.e., ampicillin-sulbactam tested in this study showed maximum effectiveness of 98.18 and 96.43 per cent towards Staphylococcus aureus and CoNS isolates, respectively, which corroborate the findings of Turutoglu et al., (2006) and Soares et al., (2012) who reported 82.00 and 100.00 per cent efficacy of ampicillin- 
sulbactam against Staphylococcus isolates, respectively.

It is quite interesting that when the isolates were tested against ampicillin-sulbactam showed maximum efficacy against Staphylococcus isolates, however these isolates showed resistant against ampicillin alone. This may be due to the fact that ampicillin-sulbactam is a combination of a $\beta$ lactam antibiotic and a $\beta$-lactamase inhibitor in which sulbactam blocks the enzyme which breaks down ampicillin and thereby allows ampicillin to attack and kill the bacteria. This also attributed due to the synergistic effect of antibiotics together. Similar observations were also made by Turutoglu et al., (2006) and Soares et al., (2012).

During the present study, $46(83.64 \%)$ and 45 (81.82 \%) isolates of Staphylococcus aureus were found sensitive to Gentamicin and Streptomycin, respectively, whereas, 27 (96.43\%) and 18 (64.29\%) CoNS isolates were found sensitive against Gentamicin and Streptomycin, respectively. This is a very good result on antibiotic susceptibility of organisms against amino glycoside group of antibiotics such as Gentamicin and Streptomycin. This might be due to the introduction of newer antibiotics in the field which have resulted in the less use of these antibiotics. Moreover, mode of development of resistance is different in case of these antibiotics.

\section{References}

Abera, M., Demie, B., Aragaw, K., Regassa, F. and Regassa, A. (2013). Isolation and identification of Staphylococcus aureus from bovine mastitic milk and their drug resistance patterns in Adama town, Ethiopia. African J. Dairy Farm Milk Prod., 1 (2): 019-023.
Abera, M., Demiel, B., Aragaw, K., Regassa, F. and Regassa, A. (2010). Isolation and identification of Staphylococcus aureus from bovine mastitic milk and their drug resistance patterns in Adama town, Ethiopia. J. Vet. Med. Anim. Health, 2 (3): 29-34.

Acar, J. and Rostel, B. (2001). Antimicrobial resistance: An Overview. Rev. Sci. Technol., 20: 797-810.

Adesola, A. E. (2012). Antimicrobial resistance pattern of Streptococci and Staphylococci isolated from cases of bovine clinical mastitis in Nigeria. Nat. Sci., 10 (11): 96-101.

Barkema, H.W., Green, M. J., Bradley, A. J. and Zadoks, R.N. (2009). Invited review: the role of contagious disease in udder health. Journal of Dairy Science 92: 4717-4729.

Bas, B. M., Muller, A. D. and Hemker, H.C. (1974). Purification and properties of Staphylo-coagulase. Biochim. Biophys. Acta., 379: 164-171.

Bergeron, M., Dauwalder, O., Gouy, M., Freydiere, A. M., Bes, M., Meugnier, H., Benito Y., Etienne, J., Lina, G., Vandenesch, F. and Boisset, S. (2011). Species identification of staphylococci by amplification and sequencing of the tuf gene compared to the gap gene and by matrix-assisted laser desorption ionization time-of-flight mass spectrometry. Eur J Clin Microbiol Infect Dis, 30:343-354

Dua, K. (2001). Incidence, etiology and estimated loss due to mastitis in India: an update. Indian Dairyman, 53: 41-48.

Duthie, E. S. (1954). Evidence for two forms of Staphylococcal Coagulase. J. Gen. Microbiol., 10: 427.

Ebrahimi, A. and Taheri, M. (2009). Characteristics of Staphylococci isolated from clinical and sub-clinical mastitis cows in Shahrekord, Iran. Iranian J. Vet. Res., 10 (3): 273-277. 
El-Jakee, J., Nagwa, A. S., Gad EI-Said, W. A., Bakry, M. A., Samy, A. A., Khairy, E. A. and Elgabry, E. A. (2010). Diversity of Staphylococcus aureus isolated from human and bovine estimated by PCR gene analysis. $J$. American Sci., 6 (11): 487-498.

Gentilini, E., Denamiel, G., Betancor, A., Rebuelto, M., Rodriguez, F. M. and deTorres, R. A. (2002). Antimicrobial susceptibility of Coagulase-negative staphylococci isolated from bovine mastitis in Argentina. J. Dairy Sci., 85: 1913-1917.

Hamadani, A. A., Khan, M. T., Ifat, A. B., Handoo, N., Bashir, A. and Hamadani, A. (2014). Bovine Mastitis - A Disease of Serious Concern for Dairy Farmers. Intl. J. Livestock Res. 3:19.

Holt, J. G., Krieg, N. R., Sneath, P. H. A., Staley, J. T. and Williams, S. T. (1994). Gram positive cocci. In: Bergey's Manual of Determinative Bacteriology, edited by Hensyl, W.R. $9^{\text {th }}$ Edn. Williams and Wilkins, Baltimore. pp. 527-558.

Kaszanyitzky, E. J., Janosi, S. Z., Egyed, Z., Agost, G. and Semjen, G. (2003). Antibiotic resistance of staphylococci from humans, food and different animal species according to data of the Hungarian resistance monitoring system in 2001. Acta Vet. Hung., 51: 451-464.

Kateete, D. P., Kimani, C. N., Katabazi, F. A., Okeng, A., Okee, M. S., Nanteza, A., Joloba, M. L. and Najjuka, F. C. (2010). Identification of Staphylococcus aureus: DNAse and Mannitol salt agar improve the efficiency of the tube Coagulase test. Annals Clin. Microbiol. Antimicrob., 9: 23.

Kumar, R., Yadav, B. R. and Singh, R. S. (2010). Genetic determinants of antibiotic resistance in aureus isolates from milk of mastitic crossbred cattle. Curr. Microbiol., 60: 379-386.
McDevitt, D., Vaudaux, P. and Foster, T. J. (1992). Genetic evidence that bound Coagulase of Staphylococcus aureus is not clumping factor. Infect. Immun., 60: 1514-1523.

Medeiros, E. S., Franca, C. A., Krewer, C. C., Peixoto, R. M., Junior, A. F. S. Cavalcante, M. B., Costa, M. M. and Mota, R. A. (2011). Antimicrobial resistance of Staphylococcus spp. isolates from cases of mastitis in Brazilian buffalo herds. J. Vet. Diagn. Invest, 23(4): 793-796.

Mekonnen, H., Workineh, S., Bayleyegn, M., Moges, A. and Taddele, K. (2005). Antimicrobial susceptibility profile of mastitis isolates from cows in three major Ethiopian dairies. Med. Vet., 176: 391-394.

Momtaz, H., Rahimi, E. and Tajbakhsh, E. (2010). Detection of some virulence factors in Staphylococcus aureus isolated from clinical and sub-clinical bovine mastitis in Iran. African $J$. Biotech., 9(25): 3753-3758.

Murugaiyah, M., Faez, F. J. A., Konto, M., Sangeetha, S. P., Lawan, A., Abdinasir, Y. O., Yusuf, A. and Abdulnasir, T. (2014). Prevalence and antimicrobial resistance assessment of sub-clinical mastitis in milk samples from selected dairy farms. American J. Anim. Vet. Sci., 9 (1): 65-70.

Parth, F. M., Chauhan, H. C., Bhagat, A. G., Chandel, B. S., Patel, B. K., Patel, K. B. and Kher, H. N. (2016). Isolation, Identification and Antibiogram of Staphylococcus aureus Isolated from Bovine Mastitis. J. Immunol. Immunopathol. 18(1): 58-62.

Rajala-Schultz, P. J., Smith, K. L., Hogan, J. S. and Love, B. C. (2004). Antimicrobial susceptibility of mastitis pathogens from first lactation and older cows. Vet. Microbiol., 102: 33-42. 
Ranjan, R., Gupta, M. K. and Kumar, S. S. (2010). Current trend of drug sensitivity in bovine mastitis. Vet. World 3: 17-20.

Rusenova, N., Gebreyes, W., Koleva, M., Mitev, J., Penev, T., Vasilev, N. and Miteva, T. (2013). Comparison of three methods for routine detection of Staphylococcus aureus isolated from bovine mastitis. Kafkas Univ. Vet. Fak. Derg., 19(4): 709-712.

Salmon, S.A. (2002). Use of antimicrobial susceptibility data to assist in determining the best therapy for clinical mastitis. In: Proc. NMC $41^{\text {st }}$ Annul Marketing, Orlando, FL. National Mastitis Council, Madison, WI. pp. 36.

Schalm, D. W. and Noorlander, D. O. (1957). Experiments and observation leading to development of the California Mastitis Test. J. American Vet. Med. Assoc., 130: 199-204.

Silva, N. C. C., Guimaraes, F. F., Manzi, M. P., Budri, P. E., Gomez-Sanz, E., Benito, D., Langoni, H., Rall, V. L. M. and Torres, C. (2013). Molecular characterisation and clonal diversity of methicillin susceptible Staphylococcus aureus in milk of cows with mastitis in Brazil. J. Dairy Sci., 96: 6856-6862.

Soares, L. C., Pereira, I. A., Pribul, B. R., Oliva, M. S., Coelho, S. M. O. and Souza, M. M. S. (2012). Antimicrobial resistance and detection of mecA and blaZ genes in Coagulase negative Staphylococcus isolated from bovine mastitis. Pesq. Vet. Bras., 32 (8): 692696.

Thaker, H. C., Brahmbhatt, M. N. and Nayak, J. B. (2013). Isolation and identification of Staphylococcus aureus from milk and milk products and their drug resistance patterns in Anand, Gujarat. Vet. Wld., 6(1): 10-13.

Turutoglu, H., Ercelik, S. and Ozturk, D. (2006). Antibiotic resistance of Staphylococcus aureus and Coagulase negative Staphylococci isolated from bovine mastitis. Bull. Vet. Inst. Pulawy., 50: 41-45.

\section{How to cite this article:}

Bhagat, A.G., H.N. Kher, A.I. Dadawala, H.C. Chauhan, M.D. Shrimali, K.B. Patel, B.K. Patel, M.A. Patel and Chandel, B.S. 2018. In vitro Antibiotic Sensitivity Pattern of Staphylococcus aureus and Coagulase Negative Staphylococci Isolated from Bovine Mastitis. Int.J.Curr.Microbiol.App.Sci. 7(10): 2962-2969. doi: https://doi.org/10.20546/ijcmas.2018.710.343 